\title{
Vinyl Sulfoxonium Ylide: A New Vinyl Carbenoid Transfer Reagent for the Synthesis of Heterocycles
}

\author{
Janakiram Vaitla*a,b \\ Annette Bayer ${ }^{b}$ \\ Kathrin H. Hopmann*a,b \\ a Hylleraas Centre for Quantum Molecular Sciences, \\ Department of Chemistry, University of Troms $\varnothing$-The Arctic \\ University of Norway, 9037 Troms $\varnothing$, Norway. \\ b Department of Chemistry, University of Troms $\varnothing-$ The Arctic \\ University of Norway, 9037 Troms $\varnothing$, Norway. \\ janakiray.vaitla@uit.no \\ kathrin.hopmann@uit.no
}

Click here to insert a dedication.

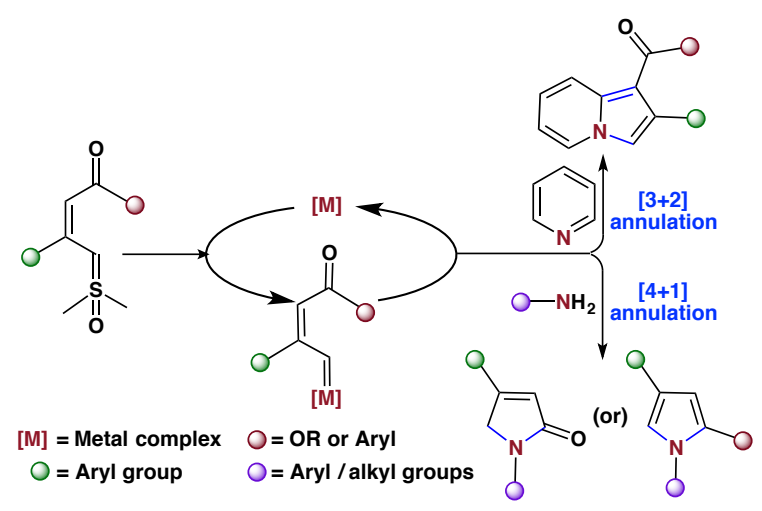

The vinyl diazo compounds $\mathbf{4 a}$ are commonly used for the generation of vinyl carbenoids through elimination of nitrogen gas. ${ }^{8}$ Since diazo compounds are considered to be potentially explosive for large scale applications, ${ }^{9}$ the use of alternative strategies for vinyl carbenoid generation such as ring opening of cyclopropenes $\mathbf{4 b},{ }^{10}$ rearrangement of propargylic esters $\mathbf{4 c},{ }^{11}$ and the attack of alkynes by a nucleophilic entity containing a leaving group $\mathbf{4 d},{ }^{12}$ has attracted attention from the synthetic community (Scheme 1). This Synpact article focuses on the use of vinyl sulfoxonium ylides $\mathbf{4 e}$ as precursors of $\mathbf{1}$, as recently described by us. ${ }^{13}$

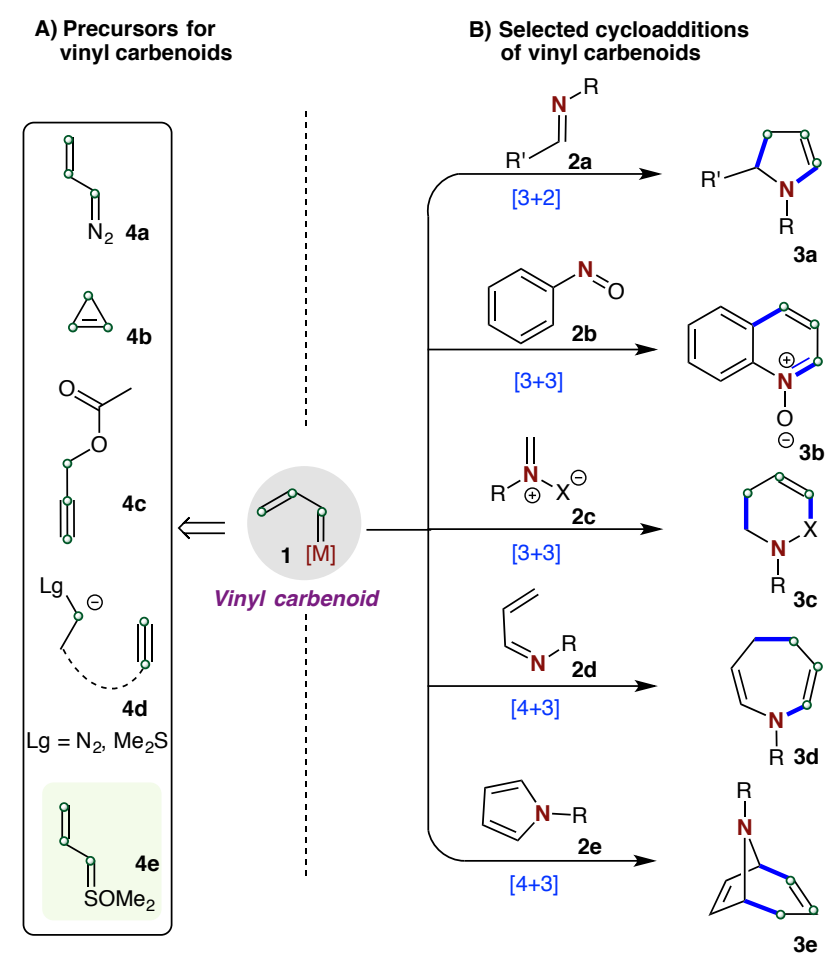

Scheme 1 Generation $^{8-12}$ and application ${ }^{3-7}$ of vinyl carbenoids

\section{Introduction}

$N$-Heterocycles are important structural frameworks for numerous natural products and pharmaceuticals. ${ }^{1}$ Cycloaddition of vinyl carbenoids with different nitrogen-based dipole or dipolarophiles is a powerful strategy to access medium-sized $\mathrm{N}$-heterocycles. ${ }^{2}$ Due to the presence of an active carbenoid carbon with an adjacent $\mathrm{C}=\mathrm{C}$ bond, vinyl carbenoid $\mathbf{1}$ acts as an efficient 3-carbon synthon in various synthetic transformations leading to diverse $N$-heterocycles (Scheme 1). Vinyl carbenoids can undergo [3+2] cycloaddition with imines $\mathbf{2 a}$, $^{3}[3+3]$ cycloadditions with nitrones $\mathbf{2} \mathbf{b}^{4}$ or azomethine imines $\mathbf{2 c},{ }^{5}$ and [4+3] cycloadditions with alkenyl imines $2 \mathbf{d}^{6}$ or pyrroles $2 \mathbf{e}^{7}$ (Scheme 1). 
Lately, the use of sulfoxonium ylides as carbenoid surrogates has been explored extensively. ${ }^{14}$ Most of the sulfoxonium ylides are bench-stable crystalline compounds, do not produce gas, and are not explosive.15 Moreover, sulfoxonium ylides possess high thermal stability when compared to diazo compounds. ${ }^{16}$ Over the past few years, sulfoxonium ylide-based metal carbenoids have been applied in $\mathrm{C}-\mathrm{C}, \mathrm{C}-\mathrm{N}, \mathrm{C}-\mathrm{O}$, and $\mathrm{C}-\mathrm{S}$ bonds formation reactions. ${ }^{14 \mathrm{~b}}$ Significantly, the iridium-catalyzed $\mathrm{N}-\mathrm{H}$ insertion of carbenoids derived from sulfoxonium ylides has been optimized for production of drug candidates on an industrial scale.17 Despite the promising applicability of sulfoxonium ylide-based carbenoids, a number of key challenges became apparent to us from reports in the field:

1) Sulfoxonium ylides can efficiently produce metal carbenoids with noble metals (Rh, Ir, Au, Pt, etc.), however, base metals (e.g. $\mathrm{Cu}, \mathrm{Fe})$ were reported to be unsuccessful. ${ }^{18}$

2) Carbenoid transfer reactions of sulfoxonium ylides other than $\alpha$-keto sulfoxonium ylides remained scarce. 19

3) Unlike diazo-derived metal carbenoids, the reactivity of metal carbenoids derived from sulfoxonium ylides had not been explored beyond insertion reactions.

4) In the presence of metals, sulfoxonium ylides could show undesired homocoupling even at room temperature..$^{20}$

Clearly, further development of sulfoxonium ylides with a focus on inexpensive and abundant catalyst systems is highly desirable. ${ }^{21}$ This objective led us to investigate the reactivity and application of vinyl sulfoxonium ylides $\mathbf{4 e}$ in sustainable catalysis. ${ }^{13}$ The present Synpacts article comprises i) a classification of sulfoxonium ylides based on their stability and reactivity, ii) a description of our working hypothesis for vinyl sulfoxonium ylides, iii) a review of our efforts in optimization of the reaction parameters, and iv) the scope of the resulting sustainable carbenoid transfer reactions.

\section{Classification of Sulfoxonium Ylides}

Sulfoxonium ylides are 1,2-dipolar compounds with a formal carbanion neighboring a positive sulfoxide group. Similar to diazo compounds, ${ }^{22}$ the stability and reactivity of sulfoxonium ylides depends on the carbanionic character of the ylide; thus, electron-withdrawing groups (such as keto, ester or amide groups) stabilize sulfoxonium ylides.

Dimethyl sulfoxonium methylide (5) (known as the Corey-Chaykovsky reagent) is a moderately stable sulfoxonium ylide, due to the absence of stabilizing groups. A solution of $\mathbf{5}$ is unstable at r.t.; however, it is stable in THF solvent under inert atmosphere at $0{ }^{\circ} \mathrm{C} .23 \mathrm{In} 2012$, Bruin and coworkers reported that 5 can be used as a one-carbon metal-carbene synthon $\left(\mathrm{M}=\mathrm{CH}_{2}\right)$ in a homopolymerization reaction (Scheme 2A).24 The mixing of the dimethyl sulfoxonium ylide $\mathbf{5}$ with a $\mathrm{Rh}$ (diene) complex lead to the rhodium complex $\mathbf{6}$, which can function as active catalyst for the polymerization of $\mathbf{5}$ to $\mathbf{7}$.

The groups of Baldwin and Mangion investigated the reactivity of acceptor stabilized sulfoxonium ylides $\mathbf{8}$ in carbenoid transfer reactions (Scheme 2B). ${ }^{18,20}$ The exposure of $\mathbf{8}$ to transition metal complexes afforded carbenoids, which underwent rapid $\mathrm{N}-\mathrm{H}$ insertion to give 9. A range of primary and secondary amines, thiols and alcohols could be applied, providing the insertion products in good yields. Recently, our group investigated the synthesis and reactivity of acceptor/acceptor stabilized sulfoxonium ylide 10 (Scheme 2c). ${ }^{25}$ Although 10 provided good yields of a variety of $\mathrm{N}-\mathrm{H}$ insertion products, the high stability of these ylides required elevated temperatures to proceed the reaction under Ir-catalysis. Under the same conditions, $\mathrm{O}-\mathrm{H}$ insertion with phenols was unsuccessful. These observations indicated to us that the reactivity of sulfoxonium ylides could be tuned through the substituents on the ylide carbon.

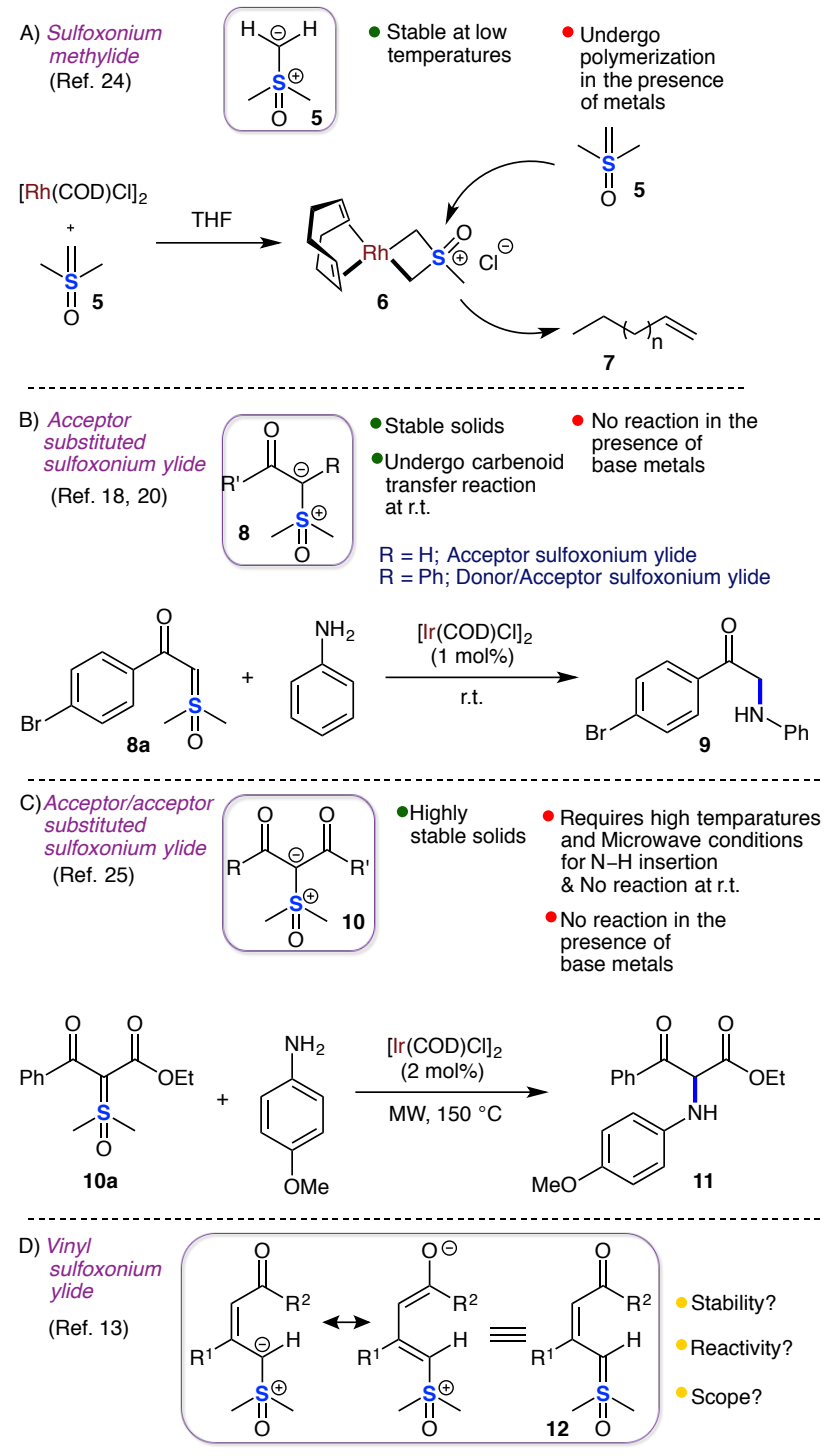

Scheme 2 Classification of sulfoxonium ylides

In general, the generation and reactivity of the carbenoid can be expected to depend on the electronic nature of the Lewis acidic metal catalyst, the nucleophilicity of the ylide carbon and the leaving group $\left(\mathrm{N}_{2}, \mathrm{Me}_{2} \mathrm{SO}, \mathrm{Me}_{2} \mathrm{~S}\right)$. In presence of strong electronwithdrawing groups, the electron density decreases at the carbanion of the ylide. As a result, highly active catalysts are required for carbenoid transfer reactions. ${ }^{26}$ We envisioned that installation of a weak electron-withdrawing group at the carbanion of the sulfoxonium ylide could attenuate its stability, and thereby increase its reactivity. In this regard, we anticipated that Michael acceptor-stabilized sulfoxonium ylides 12 (Scheme $2 D)$, which have an additional $\pi$-system between the ylide and the electron withdrawing group, could alleviate the strong stabilization at the ylide carbon. ${ }^{27}$ If successful, such ylides could 
possibly afford vinyl carbenoids from less reactive metals, may be even base metals like iron. Iron is earth-abundant, relatively cheap, and nontoxic, making it an attractive alternative to other transition metals in catalysis, ${ }^{28}$ however, iron-catalyzed vinyl carbenoid transformations had not yet been explored. ${ }^{29}$ We speculated that the reactive vinyl carbenoid species could be trapped by nucleophiles or amines followed by cyclization to give heterocycles (Scheme 3).

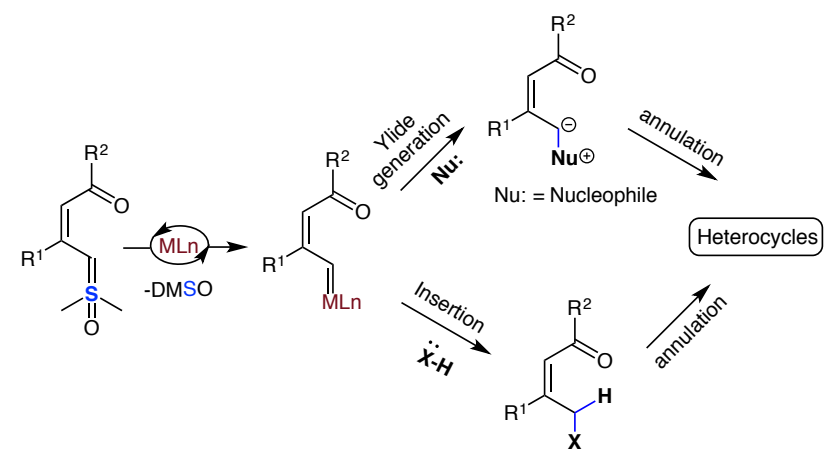

Scheme 3 Our working hypothesis for generation and application of sulfoxonium-derived vinyl carbenoids. ${ }^{13}$

\section{Synthesis of Vinyl Sulfoxonium Ylides}

The vinyl sulfoxonium ylides $\mathbf{1 2}$ can be prepared by addition of dimethyl sulfoxonium methylide $\mathbf{5}$ (generated from trimethylsulfoxonium iodide with $\mathrm{NaH}$ ) to aryl-substituted propiolates or ynones (Scheme 4). ${ }^{30}$ With respect to the stability of 12, ketone functional groups provide the more stable vinyl sulfoxonium ylides 12e-h (bench stable solids) than ester functional groups, which give the less stable 12a-d (stable at 2-8 $\left.{ }^{\circ} \mathrm{C}\right)$.

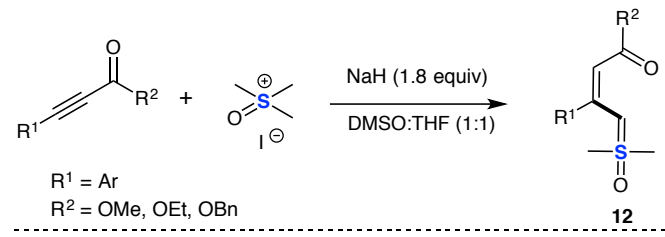<smiles>COC(=O)/C=C(/C=S(C)(C)=O)c1ccccc1</smiles><smiles>CCOC(=O)/C=C\[SH](C)(C)=O</smiles><smiles>COC(=O)/C=C(/C=S(C)(C)=O)c1cc(OC)cc(OC)c1</smiles><smiles>CS(C)(=O)=CC(=CC(=O)O)c1ccccc1</smiles>

12a: $(95 \%)$

12b: $(74 \%)$<smiles>COc1cc(OC)cc(C(=CC(=O)c2ccc(OC)c(OC)c2)C=S(C)(C)=O)c1</smiles>

12g: (61\%) 12d: $(90 \%)$<smiles>Cc1ccccc1C(=O)C=C(C=S(C)(C)=O)c1ccccc1</smiles>

12h: (85\%)
Scheme 4 Selected examples of vinyl sulfoxonium ylides synthesis. ${ }^{13}$

Preparation of $\mathbf{1 2}$ containing electron-poor aryl substituents (ester, cyano, nitro, keto substituted aryl groups) was unsuccessful. We speculate that the observed Z-selectivity of the vinyl sulfoxonium ylides is due to steric interactions between the aryl group $\left(\mathrm{R}^{1}\right)$ and the carbonyl functionality. In the case of $\mathbf{1 2 b}$, due to the absence of an aryl group, the reaction between dimethyl sulfoxonium methylide and ethyl propiolate led to a 1:10 mixture of $E$ - and $Z$-diastereomers.

\section{[3+2] annulation of Vinyl Sulfoxonium Ylides}

To verify the hypothesis in Scheme 3, we screened appropriate conditions by using vinyl sulfoxonium ylide 12a, pyridine, and various iron-based catalysts [Hemin, (TPP) $\mathrm{FeCl}, \mathrm{FeBr}_{2}, \mathrm{FeCl}_{3}$, $\left.\mathrm{FeBr}_{3}, \mathrm{Fe}(\mathrm{OTf})_{3}\right]$ for the carbenoid transfer reaction. After examining a range of iron and other metal $(\mathrm{Cu}, \mathrm{Ir}, \mathrm{Ni}, \mathrm{Zn}, \mathrm{In})$ catalysts, we found that by using $\mathrm{FeBr}_{2}(5 \mathrm{~mol} \%)$ as the catalyst, the desired product 13a was isolated in good yield (Scheme 5). Surprisingly, reaction of vinyl sulfoxonium ylide and stoichiometric amounts of $\mathrm{FeBr}_{2}$ (1.1 equiv) gave allylbrominated compound 14, which led us to evaluate the mechanistic implications of intermediates involved in our working hypothesis (Scheme 3). Suspicious of the possible involvement of 14a (via metal halo exchange of carbene) ${ }^{31}$ in the catalytic cycle, we carried out several control experiments. Reaction of allyl bromide $\mathbf{1 4}$ with pyridine in the presence of 5 mol\% of $\mathrm{FeBr}_{2}$ gave pyridinium salt, but not indolizine 13a. This result suggests that allyl bromide intermediate 14a may not be involved in the catalytic cycle for formation of 13a (Scheme 5). Despite the lack of strong spectroscopic evidence for the Fecarbene, HRMS of the reaction mixture (using $5 \mathrm{~mol} \%$ of $\mathrm{FeBr}_{2}$ ) showed dimerized ylide, consistent with a mechanistic cycle involving a metal carbene. ${ }^{32}$ The reaction afforded trace amount of 13a in the presence of other Lewis acids such as Fe(OTf)3, $\operatorname{In}(\mathrm{OTf})_{3}, \mathrm{Zn}(\mathrm{OTf})_{2}$, which indicated that the reactions proceed via a carbenoid pathway rather than simple Lewis acid activation. Based on additional computational studies performed in our group (vide infra, Scheme 10), we concluded that the observed allyl bromide $\mathbf{1 4}$ is generated from an off-cycle Fe-alkylbromide intermediate 14a, which is in rapid equilibrium with the on-cycle Fe-carbene. ${ }^{13}$
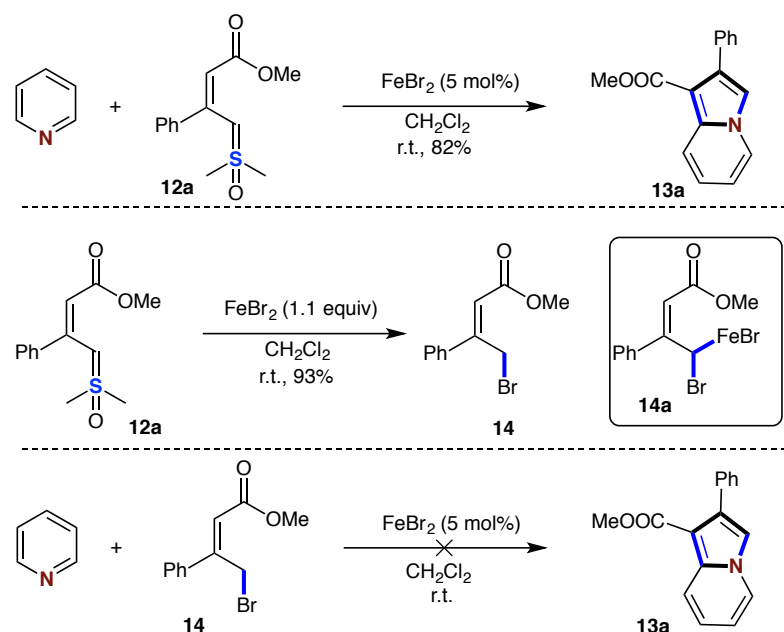

Scheme 5 Investigation of intermediates involved in the carbenoid transfer reaction. ${ }^{13}$

The substrate scope was subsequently examined under the $\mathrm{FeBr}_{2}$-catalysed conditions (Scheme 6). A wide range of vinyl sulfoxonium ylides and pyridines were effectively converted to their corresponding indolizines 13. Vinyl sulfoxonium ylides with ester functional groups were more reactive and afforded better yields of the corresponding indolizines $(\mathbf{1 3 b}-\mathbf{1 3 e})$ than 
ketone functional groups $(\mathbf{1 3 f}-\mathbf{1 3 g})$. The reaction was also successful in affording pyrroloisoquinolines $(\mathbf{1 3 h}, \mathbf{8 2} \%)$, which is the framework of lamellarins (a family of anticancer marine alkaloids). ${ }^{33}$ Also pyrroloquinolines could be formed (13i, 76\%), which are known to exhibit biological activities, including caspase activation and apoptosis induction. ${ }^{34}$

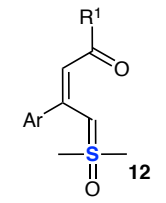

$\mathrm{R}^{1}=\mathrm{OMe}$ (or) $\mathrm{Ar}$

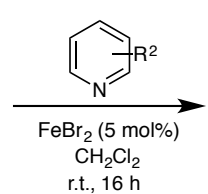

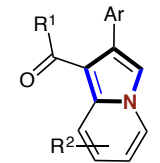
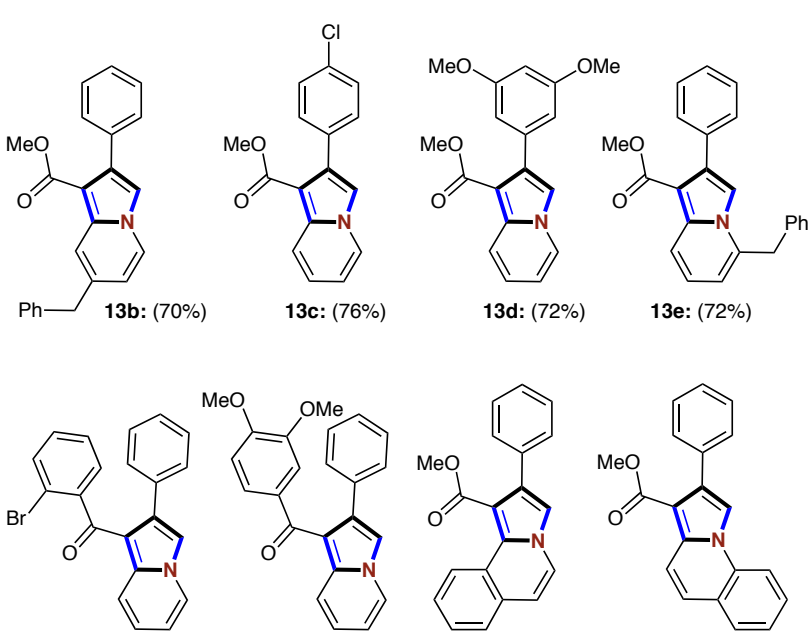

13f: $(78 \%)$

13g: (64\%)

13i: $(76 \%)$
Scheme 6 Selected examples of indolizine synthesis from vinyl sulfoxonium ylides. ${ }^{13}$

We then turned our interest to a three component synthesis of indolizine 13 (Scheme 7) directly from trimethyl sulfoxonium iodide and alkyne without isolation of the sulfoxonium ylide $\mathbf{1 2}$. In order to test this approach, sequential addition of alkyne and pyridine to the in situ generated dimethylsulfoxonium methylide, followed by addition of the $\mathrm{FeBr}_{2}$ catalyst, which indeed gave indolizine 13j, albeit in moderate yield. Interestingly, in absence of pyridine, the reaction afforded furan 15a, but only with $\left[\operatorname{Ir}(\operatorname{cod}) \mathrm{Cl}_{2}(2 \mathrm{~mol} \%)\right.$ instead of $\mathrm{FeBr}_{2}$ catalyst. Under $\mathrm{FeBr}_{2}$ catalysis, furan formation only proceeded with alkynes containing EDG groups on aryl substituents. This result support our hypothesis that electron donating aryl groups on the ylide may make the ylide carbon more reactive in the presence of iron catalysts.

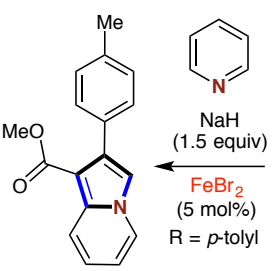

13j: (52\%)

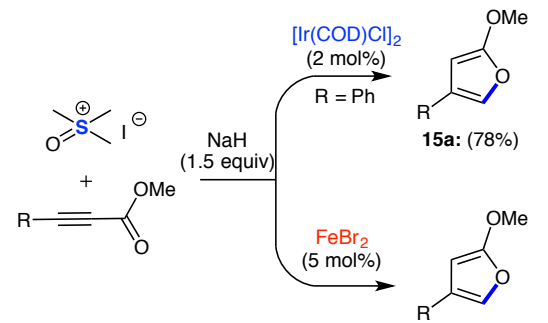

$R=3,5-$ Dimethoxyphenyl 15b: $(48 \%)$ $\mathrm{R}=\mathrm{Ph}, 15 \mathrm{a}:($ trace)
Scheme 7 One-pot generation and application of vinyl sulfoxonium ylides. ${ }^{13}$

\section{[4+1] annulation of Vinyl Sulfoxonium Ylides}

Next, to extend the scope of the vinyl carbenoids, we studied [4+1] annulation of vinyl sulfoxonium ylides with primary amines via $\mathrm{N}-\mathrm{H}$ insertion of the carbenoid (Scheme 8). Despite the recent efforts on carbenoid insertion reactions using sulfoxonium ylides, to our knowledge, there had not been any report on $\mathrm{N}-\mathrm{H}$ insertion under base metal catalysis.
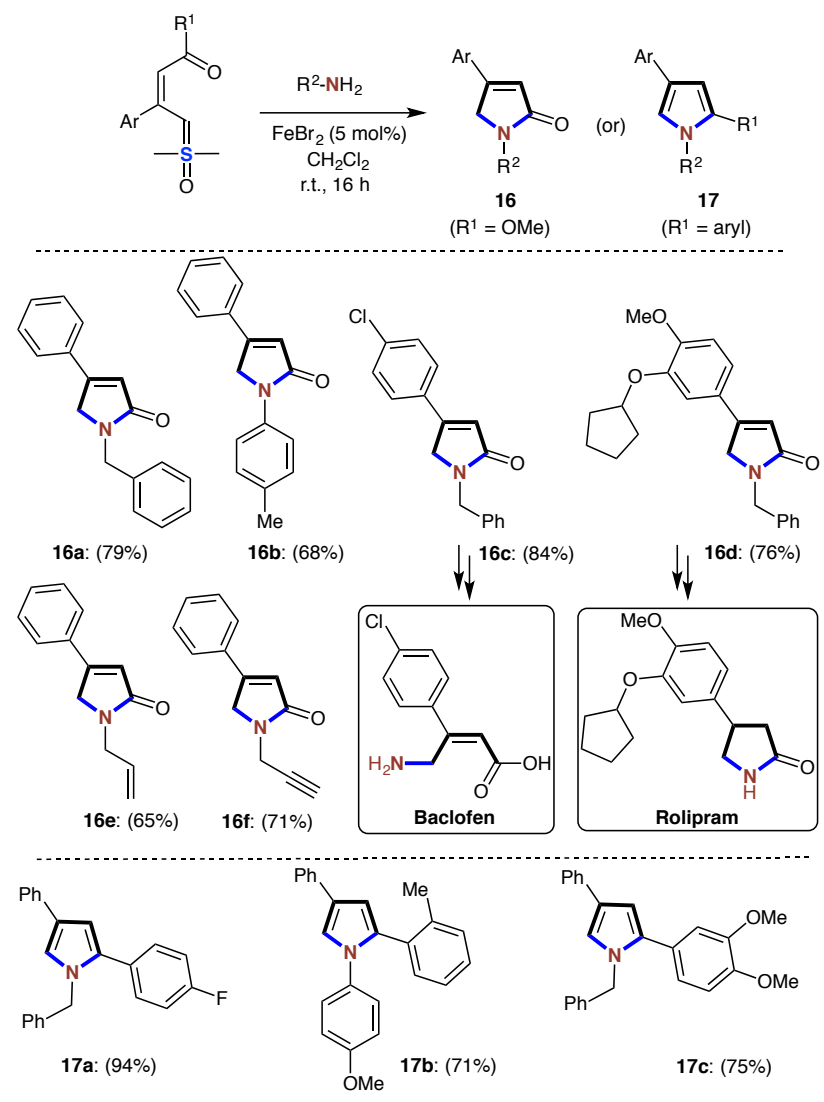

Scheme 8 Selected examples for synthesis of 3-pyrrolin-2-ones and pyrroles from vinyl sulfoxonium ylides. ${ }^{13}$

Reaction of primary amines with vinyl sulfoxonium ylides $\mathbf{1 2}$ having ester groups provided 3-pyrrolin-2-ones $\mathbf{1 6 a}-\mathbf{f}$ in the presence of $\mathrm{FeBr}_{2}$. Remarkably, allyl and propargyl amines were also converted into the corresponding 3-pyrrolin-2-ones derivatives 16e and 16f, without detectable cyclopropanation of the unsaturated bonds by the metal carbenoid intermediates. Notably, the product 3-pyrrolin-2-one $\mathbf{1 6 c}$ can be converted in 2 steps to Baclofen, ${ }^{35}$ a pharmaceutical employed in treatment of spasticity, whereas 3-pyrrolin-2-one $\mathbf{1 6 \mathbf { d }}$ can be converted in 2 steps to Rolipram, ${ }^{36}$ which is a potential antidepressant drug. Similarly, reaction of primary amines with ylides having ketone functional groups afforded 2,4-disubstituted pyrroles (17a-c), which are known to display a range of biologically important activities as HDAC inhibitors, dopamine D4 receptor modulators, and naturally occurring antibiotics. ${ }^{37}$ Whereas a previous approach for generating pyrroles from sulfoxonium ylidederived carbenoids required a precious metal catalyst at high temperatures, 38 this approach (Scheme 8) converted primary amines and vinyl sulfoxonium ylides into pyrroles using a cheap and sustainable catalyst under mild reaction conditions. ${ }^{13}$

To further explore the $\mathrm{X}-\mathrm{H}$ insertion activity of the vinyl carbenoids, ylide $\mathbf{1 2}$ was treated with secondary amines and thiols in the presence of $\mathrm{FeBr}_{2}$, which provided the corresponding insertion products in excellent yields (Scheme 9). However, the 
reaction failed to give $\mathrm{O}-\mathrm{H}$ insertion products, if ethanol or isopropanol were used as solvent.

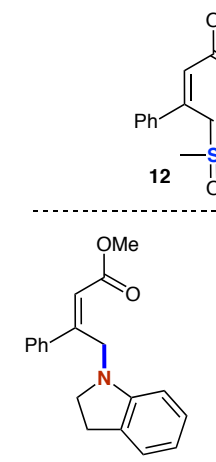

18a: $(94 \%)$

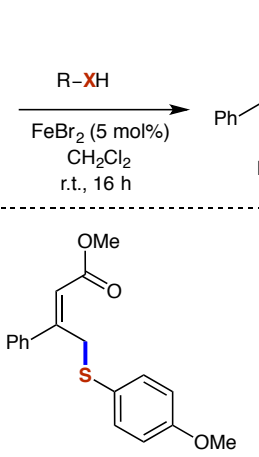

18b: $(98 \%)$
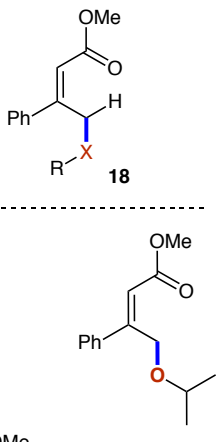

18c: $(0 \%)$
Scheme 9 Examples of $\mathrm{X}-\mathrm{H}$ insertion reactions of vinyl sulfoxonium ylide. ${ }^{13}$

On basis of our experimental observations, computational studies and literature precedents, ${ }^{39}$ we propose an overall mechanism for the observed carbenoid-mediated annulations (Scheme 10). Initially, $\mathrm{FeBr}_{2}$ reacts with the vinyl sulfoxonium ylide and generates an iron carbenoid complex by losing DMSO. Then the vinyl carbenoid can undergo attack by nucleophiles, which can be bromide (from the $\mathrm{FeBr}_{2}$ complex) or an added nucleophile, such as pyridine. According to DFT calculations, ${ }^{13} \mathrm{Br}$ attack on the carbenoid carbon has a low barrier and leads to an unstable metal-bromide inserted intermediate $\mathbf{1 4 a}$, which is an off-cycle species in rapid equilibrium with the iron-carbenoid complex. Attack of pyridine on the iron carbenoid generates pyridinium ylide, which undergoes intramolecular cyclization, followed by aromatization, leading to indolizine 13.40 Primary amines instead undergo $\mathrm{N}-\mathrm{H}$ insertion of the carbenoid followed by annulation, to give 3-pyrrolin-2-one $\mathbf{1 6}$ or pyrroles $\mathbf{1 7}$. In absence of external nucleophiles, the metal carbenoid can generate furan $\mathbf{1 5}$ via intramolecular oxygen attack on the metal carbene; this requires EDG substituted aryl groups to be successful under iron catalysis, but proceeds readily with iridium as catalyst.

\section{Conclusion}

In summary, we have discussed the background and rationale for our recent work on $\mathrm{FeBr}_{2}$-catalyzed carbenoid transfer reactions of vinyl sulfoxonium ylides. The one pot generation and utilization of vinyl sulfoxonium ylides in carbenoid transfer reactions provides a facile strategy, which is more convenient than a multistep synthesis involving enal diazo carbenoids. ${ }^{41}$ The reaction of vinyl sulfoxonium ylide-derived carbenoids with pyridines leads to indolizines via [3+2] annulation, whereas primary amines give 3-pyrrolin-2-ones and pyrroles via [4+1] annulation. The usefulness and versatility of this method was demonstrated through the synthesis of precursors for Baclofen and Rolipram. The synthetic strategy presented here is expected to have high impact on vinyl carbenoid chemistry and to find wide applications in organic synthesis.

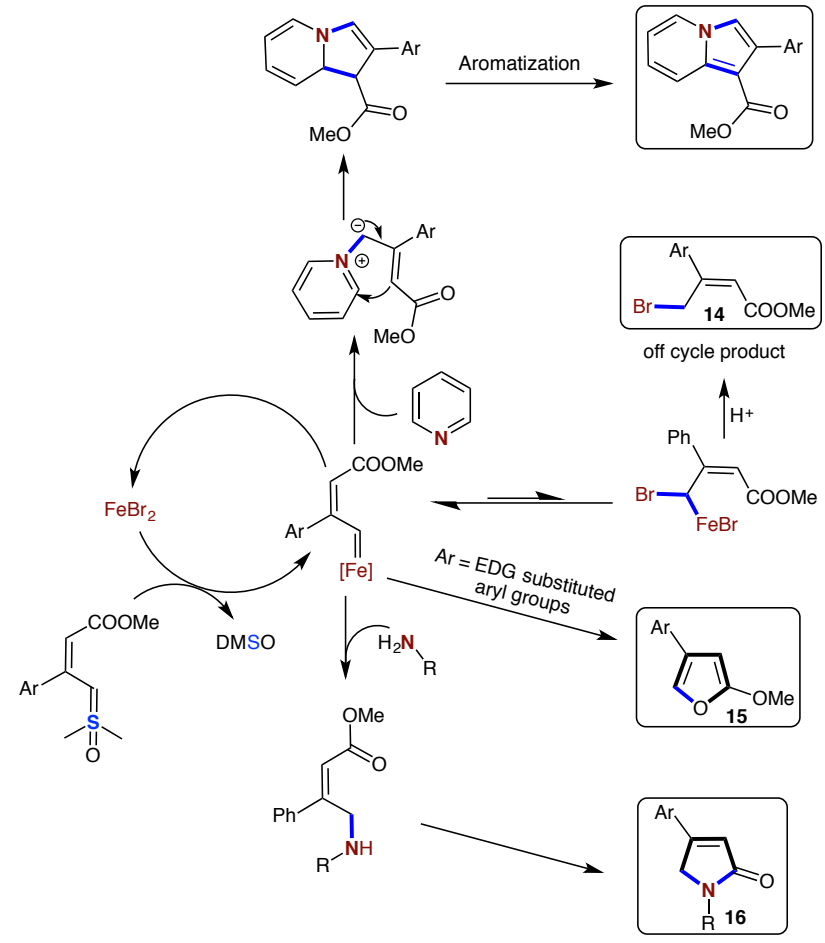

Scheme 10 Our proposed mechanism for carbenoid transfer reactions. ${ }^{13}$

\section{Funding Information}

We thank the Research Council of Norway (FRINATEK Grant No. 231706 and Centre of Excellence Grant No. 262695), the Troms $\varnothing$ Research Foundation (Grant No. TFS2016 KHH), and Nordforsk (Grant No. 85378).

\section{References}

(1)Sundberg, R. J. In Comprehensive Heterocyclic Chemistry, 2nd ed.; Bird, C. W., Ed.; Pergamon: Oxford, U.K., 1995; Vol. 2, p 121.

(2) Cheng, Q.-Q.; Yu, Y.; Yedoyan, J.; Doyle, M. P., ChemCatChem 2018, 10 , 488.

(3) Doyle, M. P.; Yan, M.; Hu, W.; Gronenberg, L. S., J. Am. Chem. Soc. 2003, $125,4692$.

(4) Wang, X.; Xu, X.; Zavalij, P. Y.; Doyle, M. P., J. Am. Chem. Soc. 2011, 133, 16402.

(5) Shapiro, N. D.; Shi, Y.; Toste, F. D., J. Am. Chem. Soc. 2009, 131, 11654.

(6) Shapiro, N. D.; Toste, F. D., J. Am. Chem. Soc. 2008, 130, 9244.

(7) Reddy, R. P.; Davies, H. M., J. Am. Chem. Soc. 2007, 129, 10312.

(8) Davies, H. M. L., Curr. Org. Chem. 1998, 2, 463.

(9) Moore, J. A.; Ree, D. E., Org. Synth. 1961, 41, 16.

(10) Archambeau, A.; Miege, F.; Meyer, C.; Cossy, J., Acc. Chem. Res. 2015, $48,1021$.

(11) Kazem Shiroodi, R.; Gevorgyan, V., Chem. Soc. Rev. 2013, 42, 4991.

(12) (a) Kramer, S.; Skrydstrup, T., Angew. Chem. Int. Ed. 2012, 51, 4681.

(b) Huang, X.; Peng, B.; Luparia, M.; Gomes, L. F. R.; Veiros, L. F.; Maulide, N., Angew. Chem. Int. Ed. 2012, 51, 8886.

(13) Vaitla, J.; Bayer, A.; Hopmann, K. H., Angew. Chem. Int. Ed. 2018, 57, 16180.

(14) (a) Burtoloso, A. C. B.; Dias, R. M. P.; Leonarczyk, I. A., Eur. J. Org. Chem. 2013, 2013, 5005. (b) Bayer, A.; Vaitla, J., Synthesis 2018, 51, 612.

(15) Neuhaus, J. D.; Oost, R.; Merad, J.; Maulide, N., Top Curr Chem (Cham) 2018, 376, 15.

(16) Janot, C.; Palamini, P.; Dobson, B. C.; Muir, J.; Aissa, C., Org. Lett. 2019, 21, 296.

(17) (a) Mangion, I. K.; Ruck, R. T.; Rivera, N.; Huffman, M. A.; Shevlin, M., Org. Lett. 2011, 13, 5480. (b) Molinaro, C.; Bulger, P. G.; Lee, E. E.; Kosjek, B.; Lau, S.; Gauvreau, D.; Howard, M. E.; Wallace, D. J.; O'Shea, P. D., J. Org. Chem. 2012, 77, 2299.

(18) Baldwin, J. E.; Adlington, R. M.; Godfrey, C. R. A.; Gollins, D. W.; Vaughan, J. G., J. Chem. Soc., Chem. Commun. 1993, 1434.

(19) Cheng, J.; Wu, X.; Sun, S.; Yu, J.-T., Synlett 2018, 30, 21.

(20) Mangion, I. K.; Nwamba, I. K.; Shevlin, M.; Huffman, M. A., Org. Lett. 2009, 11, 3566 . 
(21)Sheldon, R. A.; Arends, I. W. C. E.; Hanefeld, U. (2007). "Green Chemistry and Catalysis". doi:10.1002/9783527611003. ISBN 9783527611003

(22) Davies, H. M.; Hedley, S. J., Chem. Soc. Rev. 2007, 36, 1109.

(23) Corey, E. J.; Chaykovsky, M., J. Am. Chem. Soc. 1962, 84, 867.

(24) Suarez, A. I. O.; del Río, M. P.; Remerie, K.; Reek, J. N. H.; de Bruin, B., ACS Catal. 2012, 2, 2046.

(25) Vaitla, J.; Hopmann, K. H.; Bayer, A., Org. Lett. 2017, 19, 6688.

(26) (a) Davies, H. M. L.; Beckwith, R. E., Chem. Rev. 2003, 103, 2861. (b)

Doyle, M. P.; Forbes, D. C., Chem. Rev. 1998, 98, 911.

(27) Sun, X. L.; Tang, Y., Acc. Chem. Res. 2008, 41, 937.

(28) Bolm, C., Nat. Chem. 2009, 1, 420.

(29) (a) Zhu, S.-F.; Zhou, Q.-L., Natl. Sci. Rev. 2014, 1, 580. (b) Bauer, I.; Knolker, H. J., Chem. Rev. 2015, 115, 3170.

(30) Ide, J.; Kishida, Y., Tetrahedron Lett. 1966, 7, 1787.

(31) Goudreau, S. R.; Charette, A. B., J. Am. Chem. Soc. 2009, 131, 15633.

(32) Seitz, W. J.; Saha, A. K.; Casper, D.; Hossain, M. M., Tetrahedron Lett. 1992, 33, 7755 .

(33) Bailly, C., Mar Drugs 2015, 13, 1105.

(34) Chai, D. I.; Lautens, M., J. Org. Chem. 2009, 74, 3054.

(35) Chang, M.-Y.; Sun, P.-P.; Chen, S.-T.; Chang, N.-C., Tetrahedron Lett. 2003, 44, 5271 .

(36) Tonogaki, K.; Itami, K.; Yoshida, J., J. Am. Chem. Soc. 2006, 128, 1464. (37) Mai, A.; Valente, S.; Nebbioso, A.; Simeoni, S.; Ragno, R.; Massa, S.; Brosch, G.; De Bellis, F.; Manzo, F.; Altucci, L., Int. J. Biochem. Cell Biol. 2009, 41,235 .

\section{Biosketches}

\section{Paste photo}

in this space

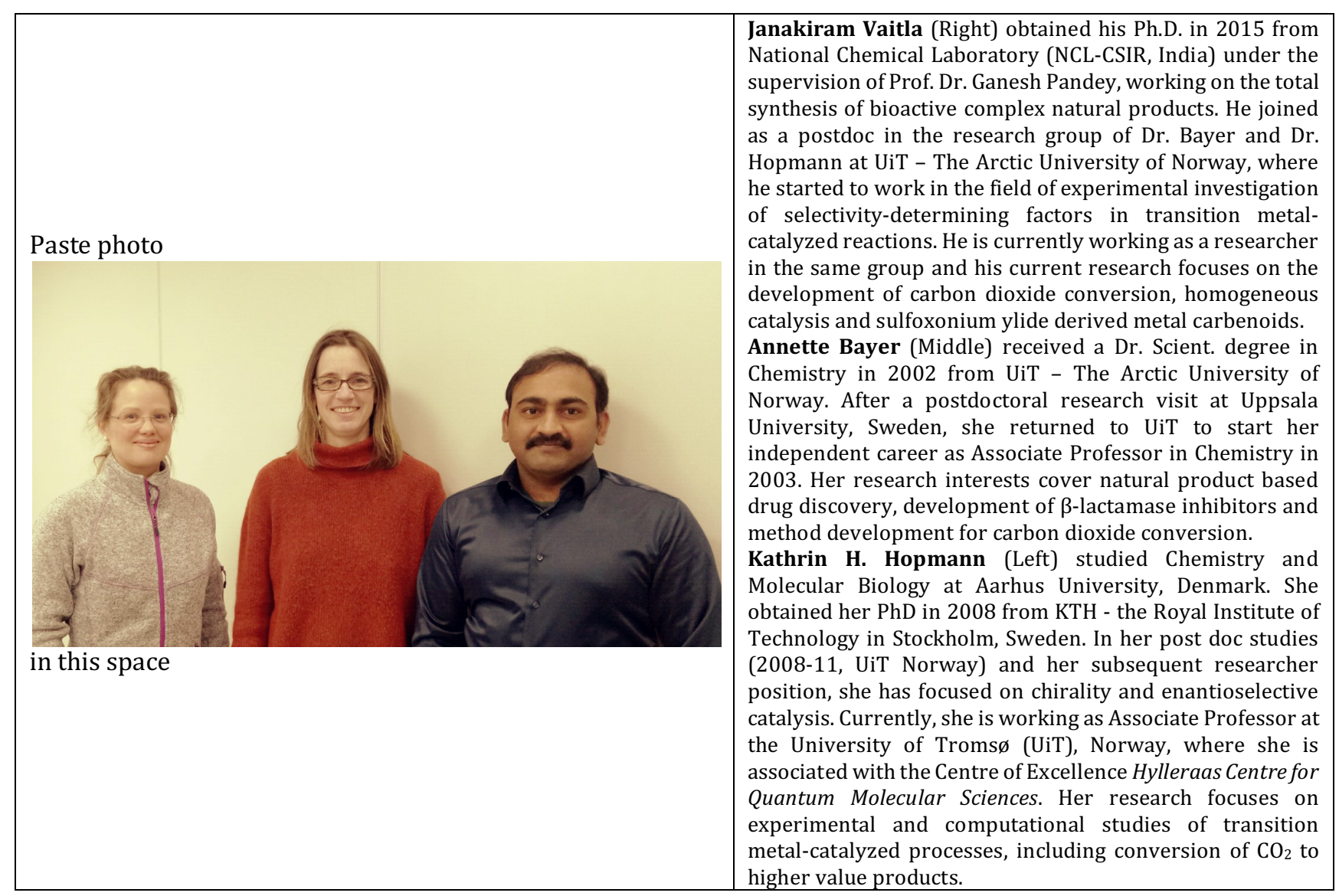

(38) Vaitla, J.; Bayer, A.; Hopmann, K. H., Angew. Chem. Int. Ed. 2017, 56, 4277.

(39) Gillingham, D.; Fei, N., Chem. Soc. Rev. 2013, 42, 4918.

(40) Barluenga, J.; Lonzi, G.; Riesgo, L.; Lopez, L. A.; Tomas, M., J. Am. Chem. Soc. 2010, 132, 13200.

(41) Dawande, S. G.; Kanchupalli, V.; Kalepu, J.; Chennamsetti, H.; Lad, B. S.; Katukojvala, S., Angew. Chem. Int. Ed. 2014, 53, 4076. 